\title{
CrimRxiv
}

\section{iA Nosotros, nos Tienen que Respetar! (They Have to Respect us!): Gangs, Inter-Generational \\ Conflict, and Graduated Governance in Urban Nicaragua}

Dennis Rodgers

Published on: Mar 01, 2022

DOI: $10.21428 / \mathrm{cb} 6 \mathrm{ab} 371.58500 \mathrm{f} 4 \mathrm{e}$

License: Creative Commons Attribution 4.0 International License (CC-BY 4.0). 
